\title{
Correction to: The Behavioral Ecology of the Tibetan Macaque
}

Jin-Hua Li, Lixing Sun, and Peter M. Kappeler

\section{Correction to:}

\author{
J.-H. Li et al. (eds.), The Behavioral Ecology of the Tibetan \\ Macaque, Fascinating Life Sciences, \\ https://doi.org/10.1007/978-3-030-27920-2
}

In the original version of the book,

The following sentence "The Chinese National Natural Science Foundation sponsored the meeting and also provided funding to support open access publication of this volume." in Acknowledgements section has been updated as follows "The National Natural Science Foundation of China sponsored the meeting and also provided funding to support open access publication of this volume, as well as the publishing fund of Hefei Normal University. Hefei Normal University also provided a fund to defray the cost of publication including book purchase."

The following sentence "This book is mainly based on research papers presented in a spirited international primatology symposium held in the scenic area of Mt. Huangshan, China, in the summer of 2017. The chapters were grouped into four logical parts." in Preface has been updated as follows "This book is mainly based on research papers presented in a spirited international primatology symposium held in the scenic area of Mt. Huangshan, China, in the summer of 2017. The chapters were grouped into five logical parts."

The following sentence "Many recent discoveries in primatology involve technological advancements in research, which is the content of Part IV. In a single chapter (Chap. 14), Yong Zhu and Paul A. Garber explore the great potential of the high field MRI technology in the study of primate behavior and

The updated online version of this book can be found at https://doi.org/10.1007/978-3-030-27920-2 
cognition." in Preface has been updated as follows "Many recent discoveries in primatology involve technological advancements in research, which is the content of Part V. In a single chapter (Chap. 14), Yong Zhu and Paul A. Garber explore the great potential of the high field MRI technology in the study of primate behavior and cognition."

Open Access This chapter is licensed under the terms of the Creative Commons Attribution 4.0 International License (http://creativecommons.org/licenses/by/4.0/), which permits use, sharing, adaptation, distribution and reproduction in any medium or format, as long as you give appropriate credit to the original author(s) and the source, provide a link to the Creative Commons licence and indicate if changes were made.

The images or other third party material in this chapter are included in the chapter's Creative Commons licence, unless indicated otherwise in a credit line to the material. If material is not included in the chapter's Creative Commons licence and your intended use is not permitted by statutory regulation or exceeds the permitted use, you will need to obtain permission directly from the copyright holder.

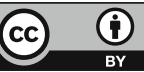

